\title{
Tekrarlayan Abdominal veya \\ Gastrointestinal Cerrahi Uygulanan Çocuklarda Lateks Duyarlılığı
}

Latex Sensitivity in Children With Recurrent Gastrointestinal Tract or Abdominal Surgical Interventions

\section{Mahmut DOĞRU ${ }^{1}$, Derya ERDOĞAN ${ }^{2}$, İlknur BOSTANCI ${ }^{1}$, Serap ÖZMEN ${ }^{1}$ İbrahim KARAMAN ${ }^{2}$, Handan DUMAN ${ }^{2}$}

1. Dr. Sami Ulus Kadın Doğum, Cocuk Sağlığı ve Hastalıkları Eğt. ve Arş. Hast., Cocuk Alerji-Immunoloji Böl. Ankara 2. Dr. Sami Ulus Kadın Doğum, Çocuk Sağlığı ve Hastalıkları Eğt. ve Arş. Hast., Çocuk Cerrahisi Bölümü, Ankara

\section{$\ddot{O Z Z E T}$}

Amaç: Lateks alerjisinin sıklığl tekrarlayan cerrahi girişimlerle artmaktadir. Bu etki özellikle spina bifidalı ve ürogenital anomalili hastalarda araştırılmıştır. Çoğunlu$\breve{g u}$ gastrointestinal sistem cerrahisi şeklinde olan ve iki veya daha fazla sayıda girişim uygulanan çocuklarda lateks alerjisi sıklığının belirlenmesi amaçlandı.

Gereç ve Yöntem: Çalışmaya Dr. Sami Ulus Kadın Doğum, Çocuk Sağlığl ve Hastalıkları Ĕgitim ve Araştırma Hastanesi Çocuk Cerrahisi Kliniğinde 01.01.2009 tarihinden önce iki ve daha üzeri sayıda cerrahi girisim uygulanmış olan 27 çocuk ile kontrol grubu olarak herhangi bir alerjik şikayeti ve cerrahi girişim geçirme öyküsü olmayan 25 sağlıkl çocuk alındl. Hasta ve kontrol grubuna aynı allerjenlerle deri prik testleri yapıldı. Total IgE düzeyi değerlendirildi.

Sonuçlar: Çalışmaya yaşları 1-24 ay olan toplam 500 infant dahil edildi. Evde sigara kullanımı hastaların $\%$ 46, 6 'sinda $(n=233)$ mevcuttu. Tekrarlayan bronşiyolit atağl geçiren çocukların, evde sigara mâruziyet oranla$r l$ istatistiksel olarak anlaml derecede yüksek saptand $(p<0,001)$.

Bulgular: Hastaların 14'ü $(\% 51,9)$ erkek olup yaşları 5 ay ile 18 yll $(5,7 \pm 4,5)$ arasinda değişmekte idi. Hastalarımızdaki tanıların dağılımında; ilk sırada sekiz $(\% 29,6)$ hastamızda bulunan anal atrezi yer almaktayken özofagus atrezisi ve korozif madde alımına bağll gastrointestinal sistem hasarı beş hasta $(\% 18,5)$ siklıkla 2. siklıktaki tanılardı. Hastalara uygulanan cerrahi girişim sayısı 2 ile 21 arasında (ortalama $\pm S D: 5,2 \pm 4$ ortanca:4) değişmekteydi. Latekse temasla gelişen bulgular, ailede alerjik hastallk, IgE yüksekliği, eozinofili, deri testlerindeki duyarlılık açısından gruplar arasında istatistiksel anlaml farklllık yoktu $(p>0,05)$. Hasta grubunun sadece birinde $(\% 3,7)$ lateks alerjisi saptanirken kontrol grubunun hiçbirinde lateks alerjisi saptanmadi.

Sonuç: Birden fazla cerrahi girişim (çoğunluğu GIS cerrahisi) uygulanan hastalarda lateks alerjisi açısından kontrole göre istatistiksel anlaml farklılik saptamadlk. Özellikle malignite nedeniyle opere olan hastalar lateksli ürünlerle sik temas ettiklerinden dikkatli izlenmelidir.

Anahtar Kelimeler: lateks alerjisi; cerrahi girişim; çocuk

\footnotetext{
İletişim Bilgileri:

Sorumlu Yazar: Mahmut Doğru

Yazışma Adresi: Dr. Sami Ulus Kadın Doğum, Çocuk Sağlığı ve Hastalıkları Eğitim ve Araştırma Hastanesi, Çocuk Alerji-İmmunoloji Bölümü, Ankara, Türkiye

E-posta: mdmahmutdogru@yahoo.com

Makalenin Geliş Tarihi: 12.02.2015

Makalenin Kabul Tarihi: 17.04.2015

DOI: http://dx.doi.org/10.16948/zktb.05694
}

\section{ABSTRACT}

Objective: The frequency of latex allergy is increased for repeated surgical interventions. This effect was investigated especially in patients with spina bifida and urogenital anomalies. There is limited data about latex allergy in repeated surgical interventions that were done for other reasons. It was aimed to determine the prevalence of latex allergy in children who underwent two or more interventions especially for gastrointestinal tract surgery.

Material and Method: A total number of 27 children who underwent two or more surgical interventions in Dr. Sami Ulus Maternity, Child Health and Diseases Training and Research Hospital Department of Pediatric Surgery before 2009, and 25 healthy children with no history of any allergic complaints and surgical intervention were included in the study. Skin prik tests were performed with the same allergens for patient and control groups. Total immunoglobulin $E$ was evaluated.

Results: The mean age was $5.7 \pm 4.5$ (5 months to 18 years) years and $51.9 \%(14)$ of the patients were male. The mean age was $5.9 \pm 1.6(2,7$ to 8,4$)$ years and $52 \%(13)$ of the children in the control group. The most diagnoses of the patients were; eight $(29.6 \%)$ patients with anal atresia, five (18.5\%) patients with esophageal atresia and five (18.5\%) patients with gastrointestinal damage due to ingestion of caustic materials. The number of surgical procedures varied between 2 to 21 (mean $\pm S D: 5.2 \pm$ 4, median: 4). Seven (26\%) patients underwent surgery more than five. Between two groups there was no significant difference for developing findings with contact to latex, family history of allergic disease, IgE elevation, eosinophilia and skin prik tests $(p<0.05)$. Latex allergy was detected in any of the control group, while only one patient $(3,7 \%)$ was allergic to latex in the patient group.

Conclusion: Children who underwent more than one surgical intervention for gastrointestinal tract was not statistically differences in terms of latex allergy compared to controls. Especially those operated for malignancy patients should be monitored carefully because they have frequent contact with latex products.

Keywords: latex allergy; surgical intervention; child 


\section{GİRIŞ}

Doğal lateks Euphorbiaceae ailesinden bir ağaç türü olan ve kauçuk ağacı olarak bilinen Hevea brasiliensis'ten elde edilmektedir. $\mathrm{Bu}$ ağacın laktifer hücrelerinden türetilen süt kıvamındaki sitoplazmik eksüda farklı işlemlerden geçirilerek değişik ürünler elde edilir. Hem dogal lateks hem de işlenmiş lateks çok sayıda allerjenik protein içermektedir. Bu proteinlere ve lateksin işlenme așamasında katılan maddelere bağlı olarak çeşitli klinik tablolar oluşmaktadır. Latekse bağlı olarak oluşan klinik tablolar iritan kontakt dermatit, alerjik kontakt dermatit, kontakt ürtiker, rinit, konjonktivit, astım ve anafilaksi şeklinde olabilmektedir. En s1k iritan kontakt dermatit şeklinde klinik tabloya yol açar (1).

Lateks alerjisi açısından çeşitli risk grupları tanımlanmıştır. Lateksle sık temas ve kişisel atopinin olması riskli gruba girmede önemlidir. En önemli riskli gruplar1; tekrarlayan maruziyete neden olan spina bifidalı ve ürogenital anomalili hastalar, sağlık personelleri, kauçuk üretiminde çalışanlar, çok sayıda cerrahi girişim uygulananlar, atopisi olanlar ve ekzeması olan hastalardır. Tekrarlayan cerrahi girişimin lateks duyarlılığındaki etkisi spina bifidalı, ürogenital anomalili ve özofagus atrezili hastalarda yap1lan çalışmalarda araştırılmıştır. Başka nedenlerle cerrahi girişim uygulananlardaki sıklık ve risk grubu olup olmadığ hakkında bilgi azdır (1-5).

Çalıșmamızda birden fazla sayıda cerrahi girişim uygulanmış olan çocuklarda lateks duyarlılığın olup olmadığı, varsa klinik özellikleri ve eşlik eden atopik hastalıkların tespit edilmesi amaçlandi.

\section{GEREÇ ve YÖNTEMLER}

Çalıșmaya, çalıșma grubu olarak Dr. Sami Ulus Kadın Doğum, Çocuk Sağlığı ve Hastalıkları Eğitim ve Araştırma Hastanesi Çocuk Cerrahisi Kliniği'nde 01.01.2009 tarihinden önce birden fazla cerrahi girişim uygulanmış olan 27 çocuk alındı. Kontrol grubu olarak ise herhangi bir alerjik şikayeti ve cerrahi girişim geçirme öyküsü olmayan 25 sağlıklı çocuk alındı. Çalışma prospektif kesitsel olarak düzenlendi. Hasta ve kontrol grubu, anne ve/veya babalarından imzalı bilgilendirilmiş onam formu alınarak çalışmaya dahil edildi.

Çalışma, Dr. Sami Ulus Kadın Doğum, Çocuk Sağlığı ve Hastalıkları Eğitim ve Araștırma Hastanesi etik kurulu tarafindan 09.01.2009 tarih ve 2009/01-21 say1l karar ile onayland1.

\section{Çalışmaya dahil edilme kriterleri}

1- Dr. Sami Ulus Kadın Doğum, Çocuk Sağlığ1 ve Hastalıkları Eğitim ve Araştırma Hastanesi Çocuk Cerrahisi Kliniği'nde 01.01.2009 tarihinden birden fazla cerrahi girişim uygulanmış olmak

2- Yaşın $<18$ yıl olması

3- Çalışmaya katılmanın kabul edilmesi

\section{Çalışma dışı bırakılma kriterleri}

1- Deri testi sonucunu etkileyen ilaçların (antihistaminik, kortikosteroid vb) alımı

3- Yaygın cilt lezyonlarının olması

4- Yakın dönemde anafilaktik reaksiyon geçirenler

5- Test sirasında anafilaksi riski yüksek olan hastalar (kötü kontrollü astımı ve solunum fonksiyon testlerinde azalması olanlar, az miktarda allerjenle ciddi anafilaktik reaksiyon öyküsü olanlar)

6- Genel durumu kötü olan hastalar

7- Beta-bloker kullanmak

Tüm hastaların ayrıntılı öyküsü alındı. Hastaların adı soyadı, doğum tarihi, cinsiyeti, hastalık tanısı, hastalık süresi, uygulanan cerrahi girişim sayısı, lateks içeren ürünlerle (eldiven, balon, emzik, biberon) temas, diş çekimi, sünnet uygulaması, lateks içeren ürünlere temasla oluşan semptomlar (kaşıntı, kızarıklık, ürtiker, dermatit, öksürük, hırıltı, nefes darlığı, burun akıntıs1, kaşıntısı, hapşırık, tıkanıklık, gözlerde sulanma, kızarma, kaşıntı, anafilaksi), kişisel-ailesel atopik hastalık öyküleri ve eşlik eden hastalıkları sorgulandı.

Çalışmaya katılanların tümünde total $\operatorname{IgE}$ düzeyi, kanda veya periferik kanda eozinofil sayımı yapıldı ve deri prik testleri uyguland.

\section{Total immunglobulin E ölçümü}

Nefelometri yöntemiyle Siemens Dade Behring BN II nephelometer (Siemens Healthcare Diagnostics Inc, Deerfield, Germany) kullanılarak yapıldı. Bu yöntemde yaşa göre normal $\mathrm{IgE}$ değerleri 0-31 gün arası $<1,5 \mathrm{IU} / \mathrm{ml}, 1$ ay-3 yaş arası $0-15 \mathrm{IU} / \mathrm{ml}, 3-6$ yaş $0-60 \mathrm{IU} / \mathrm{ml}$, 6-10 yaş $0-90 \mathrm{IU} / \mathrm{ml}, 10-16$ yaş $0-200 \mathrm{IU} / \mathrm{ml}, 16$ yaş ve erişkinde $0-100 \mathrm{IU} / \mathrm{ml}$ 'dir.

\section{Kan veya periferik kanda eozinofil sayımı}

Mikroskop altında periferik yayma ile veya tam kanda eozinofil yüzdeleri ABX Pentra 80 (HORIBAA Medical, Montpellier, France) cihazı kullanılarak elektriksel impedans yöntemi ile ölçüldü ve eozinofil sayım $\% 4^{e e}$ ün üzerinde ise eozinofili olarak değerlendirildi. 


\section{Deri prik testi uygulanması ve değerlendiril- mesi}

Spesifik antijenler her iki ön kol iç yüzüne damlatılarak Stallerpoint ${ }^{\circledR}$ ile prik yöntemle yapıld1. Pozitif kontrol olarak histamin $(10 \mathrm{mg} /$ $\mathrm{ml}$ ), negatif kontrol olarak antijen sulandirma solüsyonu (temolin) kullanıldı. On beş dakika sonra cetvel ile psödopotlar dişında endürasyonun en geniş iki çapı ölçülerek ortalama geometrik çap1 3 mm'nin üzerindeki reaksiyonlarda test pozitif kabul edildi. Standardize edilmiş 16 allerjen (Stallergenes SA, Antony, France) kullanılarak allerjen duyarlılığı araştırıldı. Deri testinde lateks, muz, kivi, kavun, domates, patates, süt, yumurta sarıs1, yumurta beyaz1, ev tozu akarı (Dermatophagoides pteronyssinus-DP), 12'li çayır polen karışımı (Lolium perenne, Dactylis glomerata, Phleum pratense, Anthoxanthum odaratum, Poa pratensis, Festuca eliator, Agrostis vulgaris, Holcus lanatus, Cynodon dactylon, Avena sativa, Avena fatua, Lotus corniculatus), 4'lü tahıl polen karışımı (yulaf, buğday, arpa, mısır), ağaç poleni karış1m1 (Acer pseudoplanatus, Aesculus hippocastanum, Robinia pseudoacacia, Tilia platyphyllos, Platanus vulgaris), Alternaria alternata, kedi epiteli ve hamamböceği (Blatella germanica) kullanıld1.

\section{İstatistiksel Analiz}

Tüm sonuçlar SPSS 17 (SPSS Inc., Chicago, IL, USA, 2009) programı ile değerlendirildi. Kesikli değişkenler sayı ve yüzde, sürekli değişkenler minimum, maksimum, ortalama \pm standart sapma ve ortanca şeklinde verildi. Kesikli değişkenlerin karşılaştırılmasında ki-kare testi kullanıldı. İki grubun normal dağılıma uygun olan sürekli değişkenlerinin karşılaştırılmasinda t-testi; iki grubun normal dağılıma uymayan sürekli değişkenlerinin karşılaştırılmasında Mann-Whitney-U testi kullanıldı. $\mathrm{p}<0.05$ değeri istatiksel olarak anlamlı kabul edildi.

\section{SONUÇLAR}

Hastaların 14'ü $(\% 51,9)$ erkek olup yaşları 5 ay ile 18 yıl $(5,7 \pm 4,5)$ arasında değişmekte idi.

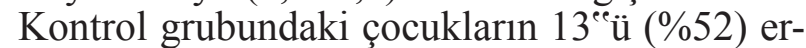
kek olup yaşları 2,7 ile 8,4 yıl $(5,9 \pm 1,6)$ arasında idi. İki grup arasında yaș ve cinsiyet açısından istatistiksel olarak anlamlı farklılık saptanmadı. Hastalarımızdaki tanıların dağılımında; ilk s1rada $8(\% 29,6)$ hastamızda bulunan anal atrezi yer almaktayken, özofagus atrezisi ve korozif madde alımına bağlı gastrointestinal sistem (GIS) hasar1 \%18,5 siklikla (5 hasta) 2. s1kliktaki tanılardı. Hasta grubumuzdaki tanıların dağılımı Tablo 1'de gösterilmiştir.

Tablo 1. Hastaların tanılara göre dağııımı.
\begin{tabular}{|l|c|c|}
\hline \multicolumn{1}{|c|}{ Anal atrezi } & $n$ & $\%$ \\
\hline Korozif madde alımına bağlı GıS hasarı & 6 & 22,2 \\
\hline Hirschsprung hastalığı & 5 & 18,5 \\
\hline Özofagus atrezisi & 4 & 14,8 \\
\hline Trakeoözofageal fistül & 4 & 14,8 \\
\hline Anal atrezi+özofagus atrezisi+ TÖF & 1 & 3,7 \\
\hline Anal atrezi+inmemiş testis & 1 & 3,7 \\
\hline Perfore nekrotizan enterokolit & 1 & 3,7 \\
\hline Akalazya & 1 & 3,7 \\
\hline Wilms tümörü & 1 & 3,7 \\
\hline Jejunal atrezi & 1 & 3,7 \\
\hline Apandektomi & 1 & 3,7 \\
\hline Anal atrezi & 1 & 3,7 \\
\hline
\end{tabular}

GIS: Gastrointestinal sistem TÖF: Trakeoözofageal fistül.

Hastaların hastalık süresi 4 ile 167 ay (ortalama \pm SD:42,8 $\pm 38,6$ ay, ortanca:31 ay) arasında değişmekte idi. Hastalara uygulanan cerrahi girişim sayısı 2 ile 21 arasında (ortalama $\pm \mathrm{SD}: 5,2 \pm 4$, ortanca:4) idi. En fazla sayıda cerrahi girişim uygulanan hastamız korozif madde alımına bağlı GİS hasarı gelişen hastamızd. Hastaların yedisine (\%26) 5 'den fazla cerrahi girișim uygulanmıștı. Hasta ve kontrol grubunun lateksle temas açısından değerlendirilmesinde; eldiven, emzik, biberon kullanımı, diş çekimi ve sünnet olma açısından istatistiksel anlamlı farklılik saptanmadi. Balonla temas öyküsü kontrol grubunun $\% 80^{\circ e}$ inde varken, hasta grubunun $\% 41$ 'inde mevcuttu. $\mathrm{Bu}$ fark istatistiksel olarak anlamliyd $1(\mathrm{p}=0,004)$. Lateks içeren ürünlere temas sonrasında oluşan klinik tablo ve semptomlar, ailede alerjik hastalik, total IgE yüksekliği, deri testlerinde duyarlılık açısından gruplar arasında anlamlı farklılık saptanmadi $(p>0,05)$ (Tablo 2).

Tablo 2. Hasta ve kontrol grubunun klinik ve laboratuar bulgularının karşılaştrilması.

\begin{tabular}{c|c|c} 
Hasta & Kontrol & \\
Grubu & Grubu \\
$(n=27)$ & $(n=25)$ & $p$ \\
\hline
\end{tabular}

\begin{tabular}{|c|c|c|c|c|c|}
\hline Dermatit & 3 & 11,1 & 2 & 8 & \multirow{3}{*}{$p>0,05$} \\
\hline Öksürük & 2 & 7,4 & \multicolumn{2}{|c|}{0} & \\
\hline Toplam & 4 & 14,8 & 2 & 8 & \\
\hline Allejik hastalık öyküsü & 5 & 18,5 & \multicolumn{2}{|c|}{0} & \\
\hline $\begin{array}{c}\text { Aiede alerjik hastalık } \\
\text { öyküsü }\end{array}$ & 7 & 25,9 & 6 & 24 & $p>0,05$ \\
\hline $\begin{array}{l}\text { İmmunglobulin E } \\
\text { yüksekliği }\end{array}$ & 5 & 18,5 & 5 & 20 & $p>0,05$ \\
\hline $\begin{array}{c}\text { Deri prik testinde } \\
\text { duyarlılık }\end{array}$ & 2 & 7,4 & 1 & 4 & $p>0,05$ \\
\hline Total serum IgE & \multicolumn{2}{|c|}{$60,8 \pm 106,5$} & \multicolumn{2}{|c|}{$49,7 \pm 93,6$} & $p>0,05$ \\
\hline Eozinofili varlığı & 2 & 7,4 & 3 & 12 & $p>0,05$ \\
\hline
\end{tabular}


Deri testlerinde lateks duyarlılığ 1 hasta grubunun 1'inde $(\% 3,4)$ saptanırken, kontrol grubundaki hiçbir çocukta saptanmadi. Lateks duyarlılığı açısından gruplar arasında istatistiksel anlamlı farkl111k bulunmadı $(\mathrm{p}=0,990)$. Latek duyarlılığı ile operasyon sayısı, hastalık süresi, atopi durumu ve 5'den fazla operasyon geçirme açısından ilişki saptanmadi.

Deri testinde görülen duyarlılıklar; hasta grubunda bir hastada hamamböceği, 1 hastada lateks ve mantar (Alternaria alternata) iken, kontrol grubunda 1 çocukta 12'li çayır karışımı ve 4'lü tahıl karışımına karşı duyarlılık saptand1. Hamamböceği duyarlılığ 1 saptanan hastanın aynı zamanda astımı da bulunmaktaydı. Lateks vemantar duyarlılığı saptanan hastamızda ise astım,AR veAE kliniği vardı. Bu hastamızda lateksle temas sonrası öksürük veiritan kontakt dermatit gelişimi öyküsü vardı. Kontrol grubunda duyarlılık saptadığımız çocuğun alerjik bulgular1 yoktu.

\section{TARTIŞMA}

Çalışmamızda tekrarlayan abdominal veya gastrointestinal cerrahi uygulanan hastalarda lateks duyarlılığı açısından kontrole göre anlamlı farklılık saptamadık. Lateks alerjisi açısından çeşitli risk grupları tanımlanmıştır. Cerrahi girişim geçirme lateks alerjisi riskini arttırırlar (1, 2, 6-8). Hourihane ve ark (6) çalışmasında daha önce yapılan herhangi bir cerrahi girişimin lateks duyarlılığını 13 kat arttırdığ 1 gösterilmiştir. Cerrahi girişim geçirenlerde lateks alerjisi gelişiminde çeşitli etkenler bulunmuştur. Bernardini ve ark (7) çalışmasında da lateks alerjisinin gelişiminde bağımsız faktörler olarak; atopi durumu ve geçirilmiş ameliyat sayısının beş veya daha fazla olması bulunmuştur. Ülkemizden Ozkaya ve ark (8) ile Bozkurt ve ark (9) çalışmalarında lateks alerjisi gelişiminde operasyon sayısı risk faktörü olarak bulunmuştur. Latekse maruziyet ile semptomların gelişmesi arasında olması gereken süre kesin olarak bilinmemektedir. Bu süreye maruziyetin sıkl1ğ1, süresi, şekli (deri, mukoza veya solunum) ve allerjen konsantrasyonunun etkisi olabilir. Maruziyet ile semptom gelişmesi arasındaki süre ile ilgili olarak Allmers ve ark (10) yapt1ğ çalışmada, bu süre yaklaşık 5 yıl $(58,7+59,3$ ay) olarak bulunmuştur. Çalışmamızda hastalarımızın hastalık süreleri 4 ile 167 ay (ortala- ma \pm SD 42,8 $\pm 38,6$ ay, ortanca:31 ay) arasında değişmekte idi. Çalışmamızda olgu sayısının ve hastalık süresinin az olmasına bağlı olarak lateks duyarlılığı açısından kontrole göre farklılık saptanmamış olabilir.

Hasta grubumuzdaki bir hasta (Wilms tümörü) hariç tümünde GİS problemleri nedeniyle cerrahi girişim uygulanmıştı. Gastrointestinel sistem cerrahi girişimlerinden sonra lateks duyarlılığ 1 ve alerjisi gelişimi ile ilgili birkaç çalışma yapılmıştır (3-5). Degenhardt ve ark (5) yaşamlarının ilk yılında GİS veya ürolojik cerrahi girişim geçiren 86 çocukta lateks duyarlılığını araştırmışlar. Ortalama yaşları 10,2 yıl olan bu çocukların 27 'sinde $(\% 31,4)$ latekse duyarlılık saptamışlardır. Cremer ve ark (3) spina bifidalı, ürogenital anomalili, özofagus atrezili ve sağlıklı çocuklarda lateks alerjisini lateks spesifik IgE ölçümü ile araştırmışlardır. Lateks duyarlılığı spina bifidalı hastalarda $\% 48$, ürogenital anomaili hastalarda \%17, özofagus atrezili hastalarda $\% 17$, kontrol grubunda $\% 4$ oranında saptanmıştır. Gentili ve ark (4) 20 özofagus atrezisi nedeniyle cerrahi girişim uygulanmış olan çocukta lateks alerjisini araştırdıkları çalışmada; beş hastada (\%25) lateks duyarlılığ 1 saptamışlardır. Bunların üçünde (\%15) lateksle klinik reaksiyon varken, ikisinde sadece spesifik IgE yüksekliğini saptamışlar. Lateks duyarlılığ 1 olanların yaş ortalaması $7,2+2,7$ yıl ve cerrahi girişim ortalaması $10,4+5,5$ olarak saptanmıştır. Lateks duyarlılığı olmayan grupta ise yaş ortalamas $5,4+3,3$ yıl ve cerrahi girişim ortalaması ise 5,1+1,4 olarak saptanmıştır. Çalışmamızda hasta grubunun yaş ortalamaS1 $(5,7 \pm 4,5$ y1l $)$ ve cerrahi girişim ortalamas $(5,2 \pm 4)$ lateks duyarlılı̆ 1 saptanmayan grupla benzerdi. Çalışmamızda da sadece bir hastada lateks duyarlılığ saptadık. Lateks alerjisinin literatürden daha az oranda bulmamızın nedeninin; çalışma grubumuzun klinik özelliklerinin farklı, yaş ortalamasının düşük, ortalama cerrahi girişim sayının az ve hastalık süresinin kısa olması olduğunu düşünüyoruz.

Lateks alerjisi saptadığımız olgumuzun cerrahi girişim sayısı dört, hastalık süresinin dokuz ay olmasına rağmen duyarlılık gelişmişti. Bunun nedeni olgunun hastalığının Wilms tümörü olması olabilir. Bostancı ve ark (11) çalışmasında hematolojik ve onkolojik hastalarda lateks alerjisi riskinin arttığı gösterilmiştir. 
Hastamız hastalığı nedeniyle daha uzun süre hastanede kalmakta ve ameliyat dışında da başka invazif girişimler uygulanmaktadır. Lateksle daha yoğun temasta olduğundan kısa sürede lateks alerjisi gelişmiş olabilir.

Çalıșmamızı sınırlayan faktör hasta grubumuzun sayısal azlığı, tip IV aracılı aşırı duyarlilik reaksiyonunun tanısinda kullanılan yama testlerinin uygulanmaması ve klinik bulguları olan hastalarda provokasyon testinin yapılmamış olmasıdır.

Sonuç olarak, birden fazla cerrahi girişim (çoğunluğu GIS cerrahisi) uygulanan hastalarda lateks alerjisi açısından kontrole göre farkl1l1k saptamadık. Özellikle malignite nedeniyle opere olan hastalar lateksli ürünlerle sık temas ettiklerinden dikkatli izlenmelidir. Bu konuda daha ileri çalışmalara ihtiyaç vardır.

\section{KAYNAKLAR}

1. Cabañes N, Igea JM, de la Hoz B, Agustín P, Blanco C, Domínguez J, Lázaro $M$, Lleonart R, Méndez J, Nieto A, Rodríguez A, Rubia N, Tabar A, Beitia JM, Dieguez MC, Martínez-Cócera C, Quirce S; Committee of Latex Allergy; SEAIC. Latex allergy: Position Paper. J Investig Allergol Clin Immunol. 2012;22(5):313-30.

2. Kelly KJ. Latex allergy. In: Leung DYM, Sampson HA, Geha R, Szefler SJ (eds). Pediatric Allergy Principles and Practice. 2nd edition. London: Saunders-Elsevier; 2010.p.631-39.

3. Cremer R, Lorbacher M, Hering F, Engelskirchen R. Natural rubber latex sensitisation and allergy in patients with spina bifida, urogenital disorders and oesophageal atresia compared with a normal paediatric population. Eur J Pediatr Surg. 2007;17(3):194-8.

4. Gentili A, Ricci G, Di Lorenzo FP, Pigna A, Masi M, Baroncini $S$. Latex allergy in children with oesophageal atresia. Paediatr Anaesth. 2003;13(8):668-75.

5. Degenhardt P, Golla S, Wahn F, Niggemann B. Latex allergy in pediatric surgery is dependent on repeated operations in the first year of life. J Pediatr Surg 2001;36:1535-9.

6- Hourihane JO, Allard JM, Wade AM, McEwan AI, Strobel $S$. Impact of repeated surgical procedures on the incidence and prevalence of latex allergy: a prospective study of 1263 children. J Pediatr 2002;140:479-82.

7- Bernardini R, Novembre E, Lombardi E, Mezzetti P, Cianferoni A, Danti AD, Mercurella A, Vierucci A.. Prevalence of and risk factors for latex sensitization in patients with spina bifida. J Urol. 1998;160(5):1775-1778.

8- Ozkaya E, Coskun Y, Turkmenoglu Y, Samanci N. Prevalance of latex sensitization and associated risk factors in Turkish children with spina bifida. Pediatr Surg Int. 2010;26(5):535-8.

9- Bozkurt G, Sackesen C, Civelek E, Kalayci O, Akalan N, Cataltepe O. Latex sensitization and allergy in children with spina bifida in Turkey. Childs Nerv Syst. 2010;26(12):173542.

10- Allmers H, Kirchner B, Huber H, Chen Z, Walther JW, Baur $X$. The latency period between exposure and the symptoms in allergy to natural latex. Suggestions for prevention. Dtsch Med Wochenschr 1996;121:823-8.

11-Bostanci I, Yılmaz R, Dallar Y, Tanyer G. Latex sensitivity in hematologic and oncologic non-atopic pediatric patients. Pediatr Asthma Allergy Immunol 2003;16(3):117-20. 